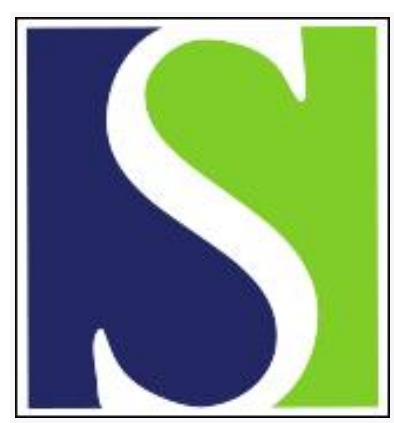

Scand J Work Environ Health 1986;12(6):631-632

https://doi.org/10.5271/sjweh.2090

Issue date: Dec 1986

Additional follow-up of cancer mortality among workers in a thermoelectric power plant.

by Cammarano G, Crosignani P, Berrino H, Berra G

This article in PubMed: www.ncbi.nlm.nih.gov/pubmed/3823815

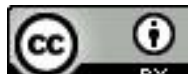




\section{Additional follow-up of cancer mortality among workers in a thermoelectric power plant}

The cohort of workers from the thermoelectric power plant of Turbigo in Milan was the subject of an earlier investigation [published in the Scandinavian Journal of Work Environment \& Health 10 (1984) 259-261]. The follow-up has now been extended to 31 December 1985, ie, for another five-year period.

An additional six deaths due to neoplasms and five due to nonneoplastic causes have occurred, for a total of 21 cancers out of 37 deaths.

As the mortality experience and expectancies of the subjects with less than 10 years of exposure do not substantially differ from those of the cohort in the earlier investigation (the person-years at risk increased from 2522 to 2801 and no death occurred), only subjects with 10 or more years of exposure have been included in this letter.

To facilitate comparability between the results, we have also included the expectancies of the previous study using new incidence rates (1), based on the data for 1987-1981 from the Lombardy Cancer Register. They are shown in table 1.

The estimate of the standardized mortality ratio for all neoplasms slightly changed (with the new rates) from 2.41 [one-sided $95 \%$ Poisson distribution-based confidence limits (95\% CL) 1.39-3.91] to 2.15 (95\% CL 1.40-3.19). The excess remained significant and could not be confined to a target organ or apparatus.

After 1978, when the first study was planned and the technological process was considered in terms of carcinogenic risk, several measures were taken to prevent exposure to such carcinogens as asbestos, polycyclic aromatic hydrocarbons, chromium, nickel, beryllium, polychlorinated biphenyls, and hydrazine. For example, areas with asbestos exposure were defined, identified and vacuum-enclosed, and only trained personnel with disposable personal protective equipment are now admitted in these areas. High-powered vacuum cleaners with automatic storage of removed material are used to prevent the spread of asbestos during the cutting of such material, the use of highspeed tools is prohibited to avoid its spread and pulverization, and polymers are spread on cutting surfaces when work is stopped to avoid its undesired spread. In addition asbestos is being substituted with ceramic fibers in the plant and with concrete in the reservoir safety walls. Fume leakage from the boilers (involving exposure to polycyclic aromatic hydrocarbons) is being monitored and, if it exceeds a predefined value, access to the area is forbidden and no operations can be performed in the area. Otherwise, the boiler is to be shut down and repaired. Skin contact with petroleum naphtha, the main source of fuel for the plant, is being prevented through the education of the workers and the use of personal protective devices. Transformers containing polychlorinated biphenyls and in the low and medium power range have been replaced, and

Table 1. Site-specific mortality for subjects in the cohort with 10 or more years of exposure. $(O=$ observed, $E=$ expected $)$

\begin{tabular}{|c|c|c|c|c|}
\hline \multirow[t]{2}{*}{ Cause of death } & \multicolumn{2}{|c|}{$\begin{array}{c}\text { Up to } 31 \\
\text { December } \\
1980\end{array}$} & \multicolumn{2}{|c|}{$\begin{array}{c}\text { Up to } 31 \\
\text { December } \\
1985\end{array}$} \\
\hline & 0 & $E$ & 0 & $E$ \\
\hline All neoplasms $(140-209)^{a}$ & 12 & 4.97 & 18 & 8.37 \\
\hline $\begin{array}{l}\text { Stomach (151) } \\
\text { Larynx (161) } \\
\text { Lung (162) } \\
\text { Colon (153) } \\
\text { Pancreas (157) } \\
\text { Breast (174) } \\
\text { Prostate (185) } \\
\text { Bladder (188) } \\
\text { Brain (191) } \\
\text { Myeloma (203) } \\
\text { Unspecified (199) }\end{array}$ & $\begin{array}{r}2 \\
1 \\
2 \\
1 \\
-1 \\
1 \\
1 \\
1 \\
1 \\
1\end{array}$ & $\begin{array}{l}0.58 \\
0.19 \\
1.71 \\
0.25 \\
0.16 \\
0.00 \\
0.11 \\
0.15 \\
0.11 \\
0.03 \\
\ldots\end{array}$ & $\begin{array}{l}3 \\
1 \\
5 \\
1 \\
1 \\
1 \\
1 \\
2 \\
1 \\
1 \\
1\end{array}$ & $\begin{array}{l}1.01 \\
0.32 \\
2.83 \\
0.44 \\
0.28 \\
0.01 \\
0.23 \\
0.27 \\
0.18 \\
0.06 \\
\ldots\end{array}$ \\
\hline Al! nonneoplastic causes ${ }^{b}$ & 10 & 10.92 & 15 & 17.67 \\
\hline
\end{tabular}

a Code of the International Classification of Diseases, ninth revision, in parentheses.

b Rates for the Varese Province, 1976-1977, from the National Institute of Health. 
high-powered transformers have been assigned to an external firm with expertise in the treatment and decontamination of polychlorinated biphenyls. Exposure to polycyclic aromatic hydrocarbons, chromium, nickel, and beryllium has been reduced by the damping of boiler ashes and the use of vacuum cleaning and filter masks during their handling. And, finally, the loading of hydrazine has been automated.

Because of the time lag between diagnosis and death, any possible effect of these preventive measures will not be observable in the data presented.

At this time, we would also like to inform readers that, due to a computing error, the nonneoplastic cause expectancy presented in table 1 of the previous paper (2) should read 5.05 for subjects with less than 10 years of exposure and 10.92 for subjects with 10 or more years of exposure.

\section{References}

1. Berrino F, Crosignani P, Gatta G, Macaluso M, Pisani $P$, Vigano' C. Registro tumori Lombardia: Incidenza e mortalita' in provincia di Varese negli anni 1978-1981. Assessorato alla Sanita' Regione Lombardia, Milano 1986. (Notizie sanita', 10).

2. Cammarano G, Crosignani P, Berrino F, Berra G. Cancer mortality among workers in a thermoelectric power plant. Scand J Work Environ Health 10 (1984) 259-261.

Giuseppe Cammarano, MD, ${ }^{1}$ Paolo Crosignani, $\mathrm{DSc},{ }^{2}$ Franco Berrino, MD, ${ }^{2}$ Giorgio Berra, $\mathrm{MD}^{3}$

${ }^{1}$ Health Service, National Board of Electricity, Turbigo Power Plant, Milan, Italy.

2 Epidemiology Unit; National Cancer Institute; 1, Venezian Rd; I-20133 Milan, Italy.

${ }^{3}$ Local Health Unit No 71, Castano Primo, Italy. 